\title{
PELATIHAN PUBLIC SPEAKING MENGGUNAKAN METODE KOOPERATIF TIPE JIGSAW DENGAN MEDIA AUDIO VISUAL PADA PEMUDA KARANG TARUNA
}

\author{
Agus Darmuki, Nur Alfin Hidayati, Syahrul Udin \\ Email: agus_darmuki@yahoo.co.id,nikidanajwasalsabila@gmail.com, \\ syahruludin@yahoo.co.id \\ IKIP PGRI Bojonegoro
}

\begin{abstract}
ABSTRAK
Salah satu aset yang akan menjadi generasi emas suatu negara yaitu pemuda. Mereka merupakan usia produktif yang memiliki potensi penggerak pembangunan suatu negara. Maju mundurnya suatu negara nanti akan bergantung pada kualitas pemuda dalam partisipasinya di pembangunan. Kemampuan mereka akan ikut andil membangun peradaban yang unggul suatu bangsa. Pemuda harus betul-betul dipersiapkan dengan berbagai kemampuan yang mendukung kehidupannya di masyarakat, salah satunya kemampuan Public Speaking. Kemampuan Public Speaking akan menjadi dasar dalam membangun peradaban bangsa yang yang demokrasi. Kemampuan Public Speaking mereka akan menunjuk.kan intelektualnya dalam menyampaikan pesan, ide, pemikiran dan informasi kepada orang lain. Tujuan kegiatan ini dengan mengadakan pelatihan public speaking bagi pemuda, untuk memberikan bekal kepada mereka kemampuan public speaking sehingga dapat berpartisipasi dalam pembangunan bangsa terutama di Desanya. Target kegiatan ini dapat menghasilkan artikel yang dipublicasikan pada jurnal. Metode yang kami pakai dalam pelatihan ini yaitu metode Kooperatif Tipe Jigsaw dengan berbasis audio visual. Melalui metode Kooperatif Tipe Jigsaw diharapkan kaum muda dapat berlatih keberanian kemudian direkam dalam bentuk audio visual dan diunggah di youtube. Kegiatan pelatihan ini dilakukan pada tanggal 4-5 November 2019. Sasaran pelatihan ini adalah pemuda karang taruna Desa Wotsogo Kecamatan Jatirogo.
\end{abstract}

Kata kunci: Pelatihan, Public Speaking, Pemuda, Kooperatif Tipe Jigsaw

\begin{abstract}
One of the assets that will become the golden generation of the country is the youth. They have many potential roles to drive the development of the country in their productive age. The development of the country in the future will depend on the quality and the participation of the youth. Their ability will contribute to build a great civilization of the nation. The young generation must be prepared with the various abilities that support
\end{abstract}


their life in society, one of which is the ability of public speaking. The ability of public speaking will be the basis to establish a democratic civilization. Their public speaking skill will show their ability in conveying messages, ideas, thoughts and information to others. The purpose of this activity is to provide some public speaking training for youth. So, they will have a skill in public speaking and can participate in the development of the country, especially in their villages. The target of this program is to produce an article that published in a journal. The method used in this training is the Jigsaw Type Cooperative method based on audio visual. Through the Jigsaw-Type Cooperative method, it is hoped that the youth can practice the courage and then record it in audio-visual form and upload it on YouTube. This training was conducted on 4-5-November 2019. The target of this training is youth organizations from Wotsogo Village, Jatirogo District.

Keywords: Training, Public Speaking, Youth, Jigsaw Type Cooperative

\section{PENDAHULUAN}

Suatu negara dikatakan maju bergantung pada keterlibatan pemuda dalam pembangunan. ${ }^{1}$ Mereka adalah aset penerus pembangunan bangsa, di tangan merekalah negara ini berharap ke depannya. Pemuda sebagai agen penerus pembangunan ini ditunjukkan salah satunya dengan kemampuan public speaking untuk menyampaikan pemikiran, pendapat \& informasi pada orang lain dengan tujuan tertentu. ${ }^{2}$ Keterampilan meraka dalam public speaking menggambarkan penguasaan pengetahuan dan intelektualnya dalam berpikir. ${ }^{3}$ Bangsa ini menggantungkan harapan besar kepada pemuda untuk memajukan bangsa ini ke arah yang lebih baik. Pemuda inilah yang akan memegang estafet kepemimpinan bangsa ini ke depan. Oleh karena itu, pembangunan harus difokuskan pada SDM dan keterampilan pemuda, salah satunya keterampilan public speaking.

Indikator keberhasilan pembangunan suatu bangsa dapat dilihat dari kualitas SDM produktifnya yaitu para pemudanya sebagai penerus bangsa yang berperan dalam pembangunan. Peningkatan keterampilan mereka bukan hanya dilakukan melalui jalur pendidikan formal, bisa juga melalui jalur nornformal. Tim PKM Prodi PBSI Fakultas Pendidikan Bahasa dan Sastra Indonesia IKIP PGRI Bojonegoro ingin mengambil peran yang strategis dengan menyiapkan SDM pemuda yang berkualitas melalui kegiatan pengabdian kepada masyarakat mengenai keterampilan public speaking. Tim PKM melalui pelatihan ini berharap dapat mengambil peran pendidikan untuk mewujudkan SDM generasi emas yang

\footnotetext{
1 Agus Darmuki Dkk., "Pelatihan MC dan Protokoler Menggunakan Metode Drill Practice dengan Media Audio Visual pada Pemuda Karang Taruna” dalam Jurnal Abdimas, 3(1), 2019, 37-46.

2 Agus Darmuki, Ahmad Hariyadi, Nur Alfin Hidayati, "Developing Beach Ball Group Investigations Cooperative", International Conferences Seword Fresh, 2019, 1-7.

3 Agus Darmuki \& N.A Hidayati, "Peningkatan Kemampuan Berbicara Menggunakan Metode Kooperatif Tipe NHT pada Mahasiswa Tingkat I-A Prodi PBSI IKIP PGRI Bojonegoro Tahun Akademik 2018/2019” dalam Jurnal Pendidikan Edutama. Vol. 6(2), 2019, 9-18.
} 
mempunyai kompetensi dan keterampilan sehingga dapat memberikan kontribusi hasil yang maksimal dan nyata untuk membekali mereka.

Kemampuan public speaking pemuda perlu memperolah perhatian khusus karena kemampuan mereka berbicara di depan umum masih jauh dari yang diharapkan. Pemuda dituntut untuk bisa tampil maksimal menguasai kemampuan public speaking sebagai tuntutan perannya dalam pembangunan di masyarakat. Meraka dituntut untuk dapat tampil di depan umum menyampaikan sumbangan ide, gagasan, pemikiran yang inovatif dan kreatif untuk pembangunan bangsa ini. Kemampuan pemuda dalam berbicara khususnya public speaking perlu diasah terus-menerus sebagai bentuk pengembangan kompetensi berbicara. Permasalahan yang terjadi, pemuda karang taruna kemampuan public speaking-nya buruk. Mereka masih banyak yang tidak mampu menyampaikan ide, gagasan, dan pemikirannya dengan baik, bahkan ketika menyampaikannya di depan umum masih banyak yang belum mampu. Ada beberapa pemuda saja yang mampu menyampaikan ide, gagasan, dan pikirannya tetapi masih nerves, grogi dan berbicaranya terbata-bata seperti orang yang baru belajar berbicara. Hal ini menunjukkan pemuda karang taruna belum kompeten berbicara khususnya public speaking. Pemuda karang taruna masih merasa tidak percaya diri, nerves, dan grogi, serta blang ketika berbicara di depan umum. Pemuda karang taruna membutuhkan pelatihan untuk berbicara khususnya public speaking yang mengutamakan praktik dan dapat menumbuhkan keterampilan sosial di masyarakat. ${ }^{4}$

Berdasarkan permasalahan di atas PKM ini dilakukan dalam bentuk pelatihan public speaking mengguanakan metode kooperatif tipe jigsaw dengan media audio visual memberikan bekal keterampilan public speaking. Selain itu, dengan menggunakan metode kooperatif tipe jigsaw dapat meningkatkan keterampilan sosial pemuda dan dengan penggunaan media audio visual memberikan ruang mereka mengekspresikan diri melalui media sehingga muncul kepercayaan dirinya. Adapun target luaran PKM ini adalah laporan PKM sesuai dengan format pedoman penulisan laporan PKM yang dibuat oleh LPPM. Luaran PKM ini berupa artikel yang akan dipublicasikan di jurnal mengenai penerapan metodel kooperatif tipe jigsaw dengan media audio visual.

\section{METODE}

Metode pelaksanaan kegiatan berupa tahapan atau langkah-langkah dalam melaksanakan pelatihan yang dimulai dari persiapan (penjadwalan), pelaksanaan, pelaporan.

Adapun tahapan pelaksanaan program yaitu:

Agus Darmuki \& Ahmad Hariyadi, "Peningkatan Keterampilan Berbicara Menggunakan Metode Kooperatif Tipe Jigsaw pada Mahasiswa PBSI Tingkat IB IKIP PGRI Bojonegoro Tahun Akademik 2018/2019”' dalam Kredo. 2(2), 2019, 256-267. 
1. Persiapan.

Adapun kegiatan-kegiatan yang akan dilakukan dalam tahap persiapan yaitu :

a) Survei tempat pelaksanaan kegiatan.

b) Pembuatan proposal dan penyalesaian administrasi perijinan tempat atau lokasi pengabdian masyarakat.

c) Pembuatan modul pembelajaran.

d) Menyiapkan dan melengkapi peralatan dan perlengkapan.

2. Pelaksanaa kegiatan.

Dalam kegiatan PKM ini, memiliki beberapa konsep dalam sebuah pembelajaran dan pembekalan materi terhadap beberapa pengetahuan Public Speaking agar dapat menerapkan kedalam kehidupan sehari-hari ataupun dalam bermasyarakat.

Tabel 2. Rencana Pelaksanaan Kegiatan

\begin{tabular}{|c|c|c|c|c|}
\hline Pertemuan & Materi Ajar & Waktu & Alat/bahan/sumber & Penilaian \\
\hline $\mathrm{Ke}-1$ & \begin{tabular}{|l} 
Perkenalan \\
Berisi pemberian motivasi \\
dan observasi awal peserta
\end{tabular} & 60 menit & Video, Proyektor, & $\begin{array}{l}\text { Keaktifan, } \\
\text { inovatif, kognitif. }\end{array}$ \\
\hline $\mathrm{Ke}-2$ & $\begin{array}{l}\text { Materi } 1 \\
\text { Pengertian public speaking }\end{array}$ & $\begin{array}{l}120 \\
\text { menit }\end{array}$ & $\begin{array}{l}\text { Video, Proyektor, } \\
\text { Praktek Lapangan }\end{array}$ & $\begin{array}{l}\text { Keaktifan, } \\
\text { inovatif, kognitif. }\end{array}$ \\
\hline $\mathrm{Ke}-3$ & $\begin{array}{l}\text { Materi } 2 \\
\text { Pentingnya kemampuan } \\
\text { public speaking dalam hidup } \\
\text { bersosial }\end{array}$ & $\begin{array}{l}120 \\
\text { menit }\end{array}$ & $\begin{array}{l}\text { Video, Proyektor, } \\
\text { Praktek Lapangan, }\end{array}$ & $\begin{array}{l}\text { Keaktifan, } \\
\text { inovatif, kognitif. }\end{array}$ \\
\hline $\mathrm{Ke}-4$ & \begin{tabular}{|l|} 
Materi 3 \\
Praktik Public Speaking
\end{tabular} & $\begin{array}{l}120 \\
\text { menit }\end{array}$ & Video, Proyektor, & $\begin{array}{l}\text { Keaktifan, } \\
\text { inovatif, kognitif. }\end{array}$ \\
\hline $\mathrm{Ke}-5$ & $\begin{array}{l}\text { Evaluasi dan rencana } \\
\text { tindak lanjut. }\end{array}$ & 30 menit & Praktek Lapangan, & $\begin{array}{l}\text { Keaktifan, } \\
\text { inovatif, kognitif. }\end{array}$ \\
\hline
\end{tabular}

3. Evaluasi.

Evaluasi ini bertujuan untuk melihat sejauh mana perkembangan program yang dilaksanakan, untuk mengetahui kendala-kendala apa saja yang ada, permasalahan-permasalahan yang ada. Untuk mengetahui cara-cara yang dilakukan untuk menanganinya sehingga program pengabdian ini dilakukan dengan dan benarbenar efektif dan juga maksimal. Evaluasi yang terakhir yaitu berupa pemberian ujian praktik public speaking.

4. Pembuatan laporan.

a. Pembuatan Laporan Awal

Pembuatan laporan awal disesaikan dengan hasil yang telah dicapai selama kurang lebih saat pembinaan terhadap pemuda karang taruna. 


\section{b. Revisi Laporan}

Revisi dilakukan apabila adanya kesalahan pada pembuatan laporan.

c. Pembuatan Laporan Akhir

Pembuatan laporan akhir dilakukan saat setelah adanya revisi, diharapkan agar laporan akhir penyusunananya diperoleh hasil yang baik.

Sedangkan metode pelaksanaan pelatihan public speaking yang berkualitas menggunakan metode kooperatif tipe jigsaw dengan media audio visual sebagai berikut:

1) Menyampaika materi mengenai public speaking menggunakan media audio visual.

2) Pemuda karang taruna dilatih membuat draf bahan berbicara di depan umum.

3) Pemuda karang taruna berlatih dengan kelompoknya menjadi public speaking secara bergantian sedangkan yang lain menjadi pengamat.

4) Pemuda karang taruna praktik menjadi public speaking dan direkam pasangannya dan bergantian untuk tampil.

5) Video rekaman diedit sebelum diunggah di youtube.

\section{ANALISIS DAN PEMBAHASAN}

Program kegiatan pengabdian dalam bentuk pelatihan bagi pemuda karang taruna yang dilaksanakan di Desa Wotsogo Kec. Jatirogo Kab. Tuban pada tanggal 4-5 Nopember 2019 di pendopo balai Desa. Pelatihan hari pertama dilaksanakan di pendopo balai desa sebagai bentuk pembukaan awal dengan menyampaikan materi dasar public speaking. Berikut foto kegiatan pertama di pendopo balai Desa Wotsogo Kec. Jatirogo Kab. Tuban.

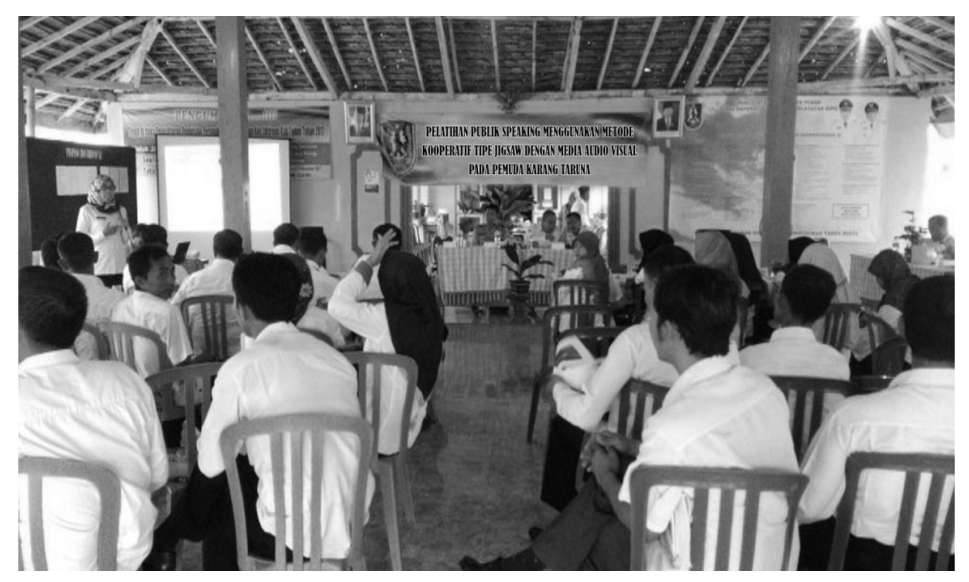

Gambar 4.1. Peserta Pelatihan public speking saat hari pertama di pendopo balai desa 
Pada hari ke dua dilaksanakan di ruang PKK dengan praktik dan secara umum kegiatan berjalan dengan baik. Program pelatihan public speaking diikuti oleh $100 \%$ pengurus pemuda karang taruna dari keseluruhan yang diundang. Peserta yang hadir 10 pria dan 7 wanita dengan total jumlah 17 orang. Penyampaian pelatihan ini menggunakan metode kooperatif tipe Jigsaw dengan media audio visual agar materi disampaikan dapat diterima baik oleh peserta tipe visual maupun auditori. Peserta pelatihan saat mengikuti kegiatan menunjukkan respon yang positif untuk belajar mendapatkan dasar materi tentang public speaking. Hal tersebut menunjukkan bahwa minat peserta pelatihan sangat relatif tinggi terlihat ketika pemateri menyampaikan materi dengan media AV (Audio Visual) tentang public speaking, para peserta PKM mendengarkan dan memperhatikan dengan serius dan seksama. Keseriusan peserta pelatihan dapat dilihat pada foto berikut.

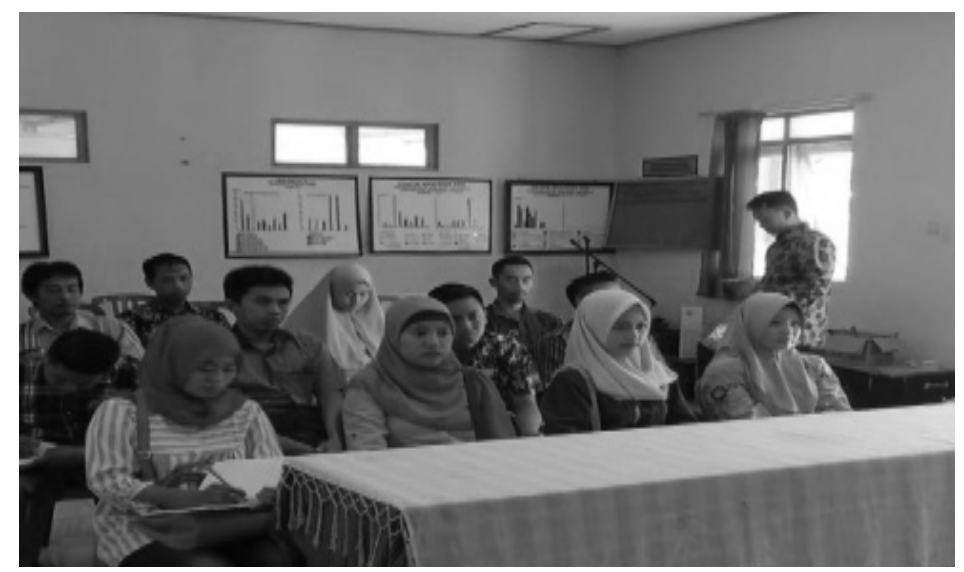

Gambar 4.2. Peserta Pelatihan public speking saat memperoleh materi di hari kedua

Foto tersebut menunjukkan bahwa antusiasme pemuda yang mengikuti pelatihan dengan serius memperhatikan tim PKM yang memberikan materi dengan AV (audio visual). Mereka bahkan ada beberapa yang mencatat hal penting dari apa yang disampaikan tim PKM. Berdasarkan observasi di lapangan bahwa dengan menggunakan media AV, bisa lebih menarik perhatian peserta pelatihan dan minat peserta terhadap PKM Public Speaking menunjukkan dampak yang positif. Hal ini sesuai temuan penelitian Madhuri yang menunjukkan dengan menggunakan AV bisa memberikan dampak positif terhadap minat belajar peserta didik. ${ }^{5}$ Kalau minat mereka terhadap pelatihan sudah positif berarti secara tidak langsung pelatihan tersebut bisa diterima baik oleh peserta.

J.N. Madhuri, "Use of Audio Visual Aids in Teaching and Speaking" dalam Research Journal of English Language and Literature, 1(3), 2013, 108-122. 
Berdasarkan wawancara eksplorasi awal sebelum kegiatan dilaksanakan menunjukkan bahwa kemampuan public speaking mereka masih kesulitan, tidak berani terutama ketika harus menyampaikan di depan banyak orang atau saat ada acara musyawarah. Mereka juga mengatakan tidak percaya diri ketika berbicara di depan umum dengan alasan takut salah, ditertawakan orang banyak, dan kalaupun berani berbicara ketika di depan umum tiba-tiba mau disampaikan blang semua. Kemampuan berbicara mereka juga masih terbata-bata, tidak lancar dan banyak keluar kata "E...." (kata jeda e....untuk menyambung kalimat). Selain itu bahasa yang mereka gunakan juga bertele-tele dan sulit untuk dipahami oleh orang lain karena bahasa yang digunakan tidak efektif serta tidak sesai dengan EYD. Ketika berbicara di depan umum mereka masih grogi dan gemetaran.

Berdasarkan observasi praktik public speaking di lapangan saat kegiatan pelatihan hari kedua menggunakan metode kooperatif dan media AV menunjukkan adannya kemajuan. Mereka sudah berani berbicara dengan lancar dan baik. Bahkan beberapa peserta yang bergantian tampil public speaking ada yang maju dengan bagus sekali, meskipun ada beberapa yang lain masih belum masksimal tetapi secara umum sudah baik. Mereka sudah tidak lagi grogi ketika diminta tampil di depan kelompoknya. Kelompok ahli yang mewakili kelompoknya bahkan sudah tampil seperti public speaking profesional.

Program pengabdian dalam bentuk pelatihan public speaking dengan media AV berdampak positif terhadap minat, dan meningkatnya pemahaman peserta pelatihan secara keseluruhan. Selain itu AV juga memberikan dampak pada suasana pelatihan lebih menyenangkan sehingga pelatihan tersebut berdampak hasil. Hal ini sesuai dengan temuan Potter menunjukkan media AV berdampak positif terhadap minat dan pemahaman peserta didik sehingga hasil pembelajaran pun miningkat. ${ }^{6}$ Penggunaan media AV sangat membantu tim PKM untuk memaparkan materi dalam bentuk AV sehingga dengan mudah dapat diterima oleh peserta pelatihan. Selanjutnya mereka diminta berlatih berpasangan sebelum mereka praktik di depan secara langsung.

Program pengabdian dalam bentuk pelatihan public speaking dengan metode Kooperatif tipe Jigsaw memberikan pengaruh keberanian, kecerdasan sosial, dan peningkatan kepercayaan diri bagi peserta pelatihan. Hal ini sesuai dengan temuan penelitian Darmuki dan Hidayati bahwa dengan menggunakan metode kooperatif dapat meningkatkan kecerdasan sosial peserta didik karena mereka dilatih untuk membentuk kelompok untuk bekerja sama. ${ }^{7}$ Keberanian dan kepercayaan diri serta kecerdasan sosial muncul karena sebelumnya mereka diberikan kesempatan tampil di kelompok kecilnya sebelum ditetapkan sebagai

${ }^{6}$ J. Potter, "This Brings Back a Lot of Memories'- A Case Study in the Analysis of Digital Video Production by Young Learners" dalam Education, Communication \& Information, 5(1), 2005, 5-23.

7 Agus Darmuki \& N.A. Hidayati, "An Investigation of The Cooperative Learning Using Audio Visual Media in Speaking Skill Subject" dalam ICSTI, 2019, 121-126. 
perwakilan kelompoknya. Hal ini sesuai dengan pendapat Slavin bahwa metode kooperatif dapat menumbuhkan keberanian dan kepercayaan diri seseorang dan berdampak pada kecerdasan sosial melalui kerja kelompok karena metode kooperatif memberikan kesempatan tampil dikelompok kecilnya sebelum terpilih menjadi kelompok ahli. ${ }^{8}$

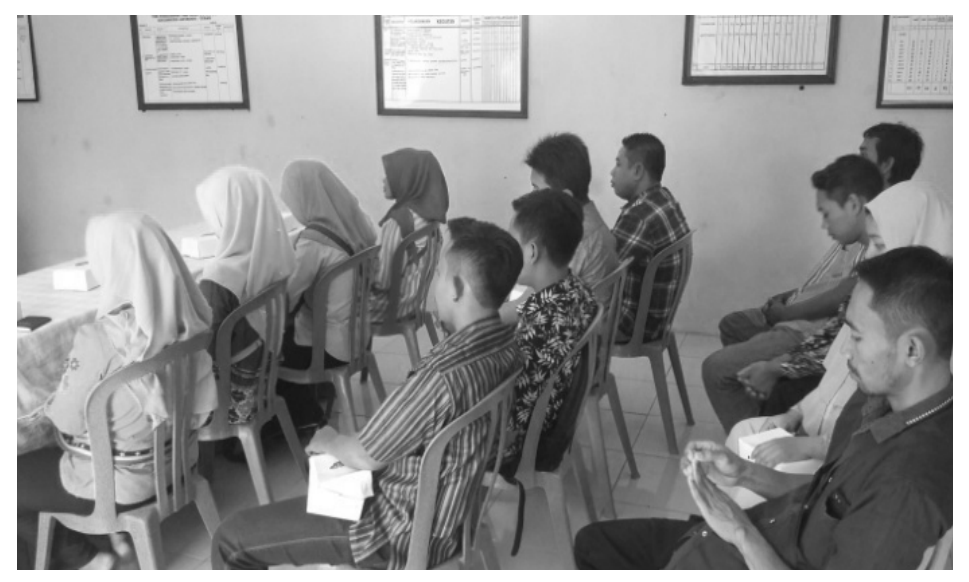

Gambar 3. Peserta Pelatihan Saat memperhatikan penjelasan tentang MC

Pelatihan diakhiri dengan demonstrasi/simulasi (praktik menjadi seorang public speaking) yang dilakukan oleh para peserta pelatihan. Masing-masing peserta dipersilahkan memilih acara yang akan dibawakannya sebagai public speaking. Peserta langsung mengaplikasikan berbagai materi yang telah disampaikan pemateri tentang berperan sebagai public speaking yang baik, meliputi penggunaan bahasa, pengaturan suara, sikap, kostum, kontak audien dan aspek lain dari seorang public speaking dengan berpraktik sebagai seorang public speaking. Penampilan peserta sebagai public speaking dievaluasi bersama- sama oleh pemateri dengan menerima masukan dari peserta yang lain. Dari praktik yang dilakukan oleh peserta pelatihan setelah menerima materi, terlihat bahwa keterampilan dan kemampuan mereka dalam berperan sebagai public speaking mengalami perbaikan jika dilihat dari berbagai aspek tugas public speaking. Hal ini sesuai pendapat Hughes ${ }^{9}$ dan Thornbury ${ }^{10}$, bahwa keterampilan berbicara membutuhkan latihan terus-menerus untuk memperoleh hasil yang maksimal. Berikut hasil praktik public speaking yang dilaksanakan peserta pelatihan saat pretes maupun postes.

\footnotetext{
8 Robert E. Slavin, Cooperative Learning Teori, Riset dan Praktik. (Bandung: Nusa Media, 2019), 20.

$9 \quad$ R. Hughes, Teaching and Researching Speaking (Great Britain: Longman, 2002), 54.

10 S. Thornbury, How to Teach Speaking (Pearson: Longman, 2005), 20.
} 
Tabel 2. Rekap Hasil Praktik MC

\begin{tabular}{lcc}
\hline \multicolumn{1}{c}{ Indikator } & $\begin{array}{c}\text { Nilai } \\
\text { Rata-Rata Pretes }\end{array}$ & $\begin{array}{c}\text { Nilai } \\
\text { Rata-Rata Postes }\end{array}$ \\
\hline Kalimat Efektif (pilihan kata) & $43,36 \%$ & $76,47 \%$ \\
\hline Intonasi (tinggi rendahnya suara) & $27,64 \%$ & $75 \%$ \\
\hline Ekspresi & $23,53 \%$ & $94,11 \%$ \\
\hline Kostum & $32,35 \%$ & $64,70 \%$ \\
\hline Kontak audien & $26,32 \%$ & $76,47 \%$ \\
\hline
\end{tabular}

Berdasarkan hasil postes di atas menunjukkan bahwa penggunaan kooperatif tipe jigsaw dengan media audio visual dapat meningkatkan keterampilan peserta pelatihan public speaking. Peningkatan keterampilan peserta pelatihan dapat dilihat dari hasil postes nilai rata-rata kalimat efektif peserta public speaking sebanyak 13 orang atau 76, 47\%, dari aspek intonasi sebanyak 12 orang atau $75 \%$, peserta pelatihan memiliki ekspresi sebanyak 16 orang atau $94,11 \%$, dari aspek kostum sebanyak 11 orang atau 64,70\%, kemudian dari aspek kontak dengan audien sebanyak 11 orang atau 68,47\%.

Pada awal pelatiha public speaking, tim PKM memberikan soal pre tes untuk mengetahui pengetahuan mengenai public speaking peserta pelatihan. Setelah tim menyampaikan materi dan telah melakukan praktik sebagai public speaking satu persatu tim pengabdian memberikan postes kepada peserta untuk mengetahui tingkat keberhasilan pengabdian yang dilakukan oleh tim terkait pengetahuan dan pemahaman sebagai public speaking. Soal postes yang diberikan kepada peserta pelatihan sama dengan soal pada pretes. Hasil pretes dan postes pada pelatihan public speaking dapat digambarkan pada tabel berikut.

Tabel 3. Rekap Hasil Pretes dan Postes

\begin{tabular}{lcc}
\hline \multicolumn{1}{c}{ Indikator } & Nilai Pretes & Nilai Postes \\
\hline $\begin{array}{l}\text { Apakah anda memiliki pengetahuan sebagai MC } \\
\text { dan Protokoler }\end{array}$ & $18,75 \%$ & $93,75 \%$ \\
\hline Bisa mempraktikkan sebagai MC dan Protokoler & $12,5 \%$ & $100 \%$ \\
\hline $\begin{array}{l}\text { Apakah anda memiliki skill sebagai MC dan } \\
\text { Protokoler }\end{array}$ & $12,5 \%$ & $93,75 \%$ \\
\hline $\begin{array}{l}\text { Apakah anda memiliki sikap seorang MC dan } \\
\text { Protokoler }\end{array}$ & $31,25 \%$ & $81,25 \%$ \\
\hline $\begin{array}{l}\text { Apakah anda memiliki kepercayaan diri ketika } \\
\text { menjadi MC dan Protokoler }\end{array}$ & $25 \%$ & $87,5 \%$ \\
\hline
\end{tabular}


Hasil postes menunjukkan bahwa peserta pelatihan memiliki pengetahuan sebagai public speaking sebanyak 15 orang atau 93,75\%, dapat mempraktikkan sebagai public speaking sebanyak 16 orang atau $100 \%$, memiliki skill sebagai public speaking menurut 15 orang atau 93,75\%, memiliki sikap seorang public speaking sebanyak 13 orang atau 81,25\%, dan peserta memiliki kepercayaan diri ketika menjadi public speaking sebanyak 14 orang atau 87,5\%. Secara umum kegiatan PKM Pelatihan public speaking pada pemuda karang taruna menggunakan metode kooperatif tipe Jigsaw dengan media AV berjalan dengan baik dan dapat menumbuhkan kepercayaan diri, kecerdasan sosial, menambah pengetahuan dan pemahaman tentang kegiatan public speaking.

Hasil luaran yang sudah dicapai dalam kegiatan PKM ini berupa laporan PKM dan artikel yang sudah di submit di jurnal pengabdian masyarakat yang akan terbit tahun 2020 . Secara umum luaran sudah tercapai sesuai dengan target yang dijanjikan oleh tim PKM yaitu berupa laporan PKM dan artikel ke jurnal penabdian. Laporan PKM telah dibuat sesuai dengan pedoman laporan pengabdian kepada masyarakat edisi 2018. Artikel yang di submit di jurnal telah sesuai dengan template jurnal yang dituju.

\section{KESIMPULAN}

Program kegiatan pengabdian yang tim PKM lakukan sudah berjalan sesuai rencana dengan lancar dan baik meskipun dengan waktu yang terbatas. Program tersebut memperoleh respon yang baik dari pemuda yang telah mengikuti pelatihan public speaking. Apresiasi yang positif juga diberikan oleh pemerintahan Desa Wotsogo Kec. Jatirogo Kab. Tuban terhadap program dari tim PKM kami. Tujuan tim PKM dalam melaksanakan program PKM telah berjalan secara baik yaitu untuk memberikan pelatihan pubic speaking kepada pemuda karang taruna telah tercapai. Secara umum pemuda karang taruna telah memiliki kemampuan public speaking yang dapat digunakan untuk berpartisipasi dalam pembangunan dengan cara menyampaikan aspirasi, ide, gagasan, dan pemikirannya kepada masyarakat di depan umum.

Berdasarkan hasil dan simpulan di atas, saran dari tim kami diantaranya adalah sangat diperlukan kegiatan PKM pelatihan public speaking tingkat lanjut untuk semakin menguasai keterampilan mereka dalam praktik nyata di dalam masyarakat misalnya dalam kegiatan musyawarah Desa, musyawarah organisasi karang taruna, reorganisasi karang taruna dan kegiatan musyawarah lainnya. Kemudian perlu adanya kerjasama dengan pihak-pihak terkait dalam memaksimalkan keterlibatan peran pemuda dalam pembangunan desa, bangsa dan, negara tercinta sehingga kualitas public speaking mereka tersalurkan dalam kehidupan bermasyarakat misalnya pihak humas pemerintah Kabupaten Tuban dari Desa, Kecamatan sampai Kabupaten. 


\section{DAFTAR PUSTAKA}

Darmuki, A. \& Ahmad Hariyadi. (2019). Eksperimentasi Model Pembelajaran Jucama Ditinjau Dari Gaya Belajar Terhadap Prestasi Belajar Mahasiswa Mata Kuliah Berbicara Di Prodi PBSI IKIP PGRI Bojonegoro. Kredo. 3 (1), 62-72.

Darmuki, A. \& Hidayati N.A. (2019). An Investigation of The Cooperative Learning Using Audio Visual Media in Speaking Skill Subject. ICSTI. 121-126.

Darmuki, A. \& Hidayati, N.A. (2019). Peningkatan Kemampuan Berbicara Menggunakan Metode Kooperatif Tipe NHT pada Mahasiswa Tingkat I-A Prodi PBSI IKIP PGRI Bojonegoro Tahun Akademik 2018/2019. Jurnal Pendidikan Edutama. Vol. 6(2), hlm 9-18.

Darmuki, A., Ahmad Hariyadi. (2019). Peningkatan Keterampilan Berbicara Menggunakan Metode Kooperatif Tipe Jigsaw pada Mahasiswa PBSI Tingkat IB IKIP PGRI Bojonegoro Tahun Akademik 2018/2019. Kredo. 2(2), 256-267.

Darmuki, A., Andayani, Joko Nurkamto, Kundharu Saddhono. (2017). Cooperative, Synectics, and CTL Learning Models Toward Speaking Ability Viewd from Students Motivation. Proceeding International Conference on Intellectuals'Global Responsibility (ASSEHR). Vol. 125, 75-79.

Darmuki, A., Andayani, Joko Nurkamto, Kundharu Saddhono. (2017). Evaluating Information-Processing-Based Learning Cooperative Model on Speaking Skill Course. Journal of Language Teaching and Reasearch. 8(1) pp. 44-51.

Darmuki, A., Andayani, Joko Nurkamto, Kundharu Saddhono. (2018). The Development and Evaluation of Speaking Learning Model by Cooperative Approach. International Journal of Instruction. 11(2), 115-128.

Darmuki, A., Ahmad Hariyadi, Nur Alfin Hidayati. (2019). Developing Beach Ball Group Investigations Cooperative. International Conferences Seword Fresh, 1-7.

Darmuki, A., Andayani, Joko Nurkamto \& Kundharu Saddhono. (2018). The Development and Evaluation of Speaking Learning Model by Cooperative Approach. International Journal of Instruction. 11(2) pp. 115-128.

Darmuki, A., M. Sholehuddin, Nur Alfin Hidayati, Sutrimah. (2019). Pelatihan MC dan Protokoler Menggunakan Metode Drill Practice dengan Media Audio Visual pada Pemuda Karang Taruna. J-Abdimas. 3(1), 37-46

Darmuki, A., Nur Alfin Hidayati. (2019). An Investigation of The Cooperative Learning Using Audio Visual Media in Speaking Skill Subject. Proceedings of the 1st International Conference on Science and Technology for an Internet of Things. DOI:10.4108/eai.19-102018.2282555

Hughes, R. (2002). Teaching and researching speaking. Great Britain: Longman.

Madhuri, J. N. (2013). Use of Audio Visual Aids in Teaching and Speaking. Research Journal of English Language and Literature, 1(3), 108-122. 
Potter, J. (2005). 'This brings back a lot of memories'- A Case Study in the Analysis of Digital Video Production by Young Learners. Education, Communication \& Information, 5(1), 5-23.

Slavin, Robert E. (2009). Cooperative Learning Teori, Riset dan Praktik. Bandung: Nusa Media. Thornbury, S. (2005). How to Teach Speaking (J. Harmer. ed.). Pearson: Longman. 